\title{
Can the MTT Assay Be Optimized to Assess Cell Proliferation for Use in Cytokine Measurement?
}

\author{
Elisa Vega-Avila ${ }^{1 *}$, Michael K. Pugsley ${ }^{2}$ \\ 'División de Ciencias Biológicas y de la Salud, Universidad Autónoma Metropolitana, Unidad Iztapalapa, México \\ ${ }^{2}$ Department of Toxicology \& PKDM, Purdue Pharma L.P., Stamford, CT, 06901, USA
}

\section{*Correspondence to Elisa Vega-Avila, Email:} evegavila@yahoo.com.mx

Received June 1, 2017 Accepted June 17, 2017 Published online June 30, 2017

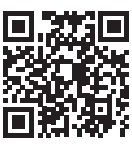

Please cite this article as follows: Vega-Avila E, Pugsley MK. Can the MTT assay be optimized to assess cell proliferation for use in cytokine measurement? Int J Basic Sci Med. 2017;2(2):7376. doi:10.15171/ ijbms.2017.14.
Dear Editor

We read with great interest the article by Molaee et al entitled "Evaluating the proliferation of Human Peripheral Blood Mononuclear Cells Using MTT assay" that was recently published in the International Journal of Basic Science in Medicine. ${ }^{1}$

The findings described in this publication have utilized the colorimetric 3-(4,5-dimethylthiazol2yl)-2,5-diphenyl tetrazolium bromide (MTT) assay. ${ }^{2}$ As we have previously reviewed, ${ }^{3}$ the MTT assay was described in the early 1980s with multiple subsequent modification $s^{4,5}$ to enhance assay conditions. Currently it is a prominent, sensitive, quantitative, and reliable colorimetric assay that measures viability, proliferation, and activation of cells. In order to appreciate the data generated by Molaee et al using the MTT assay, the readers should understand some fundamentals regarding the nature of the assay. In drug research and development, utility of the assay in preclinical testing includes, in particular, its use as an early in vitro oncology-related drug assessment assay and a method to assess immune-stimulation. The assay principle is simply based on the capacity of the cellular mitochondrial dehydrogenase enzyme in living cells to reduce the yellow water-soluble substrate MTT into a dark blue/purple formazan product which is insoluble in water. The amount of formazan produced is directly proportional to the cell number in a range of cell lines. ${ }^{2}$ The MTT assay has greater application in the detection of cells which are not dividing but are still metabolically active. It can, therefore, be used to distinguish between proliferation and cell activation. ${ }^{6}$ An additional advantage to the assay is that it can be used in suspend- ed or monolayer cell preparations. ${ }^{7,8}$ Unfortunately, during the conduct of the test, cells die making it impossible to do follow-up cell culture assessments.

The authors utilized a Ficoll-Hypaque density gradient ${ }^{9}$ to isolate the peripheral blood mononuclear cells (a mixture of monocytes and lymphocytes) from whole blood and tested the effect of various mitogens on the rate of cell proliferation using the MTT assay. 3,7 The Ficoll-Hypaque gradient is a standard, rapid and simple centrifugation method used for the separation of peripheral blood mononuclear cells (PBMC). The assay utilizes density differences to separate formed blood elements such as leukocytes and erythrocytes from mononuclear cells. ${ }^{10}$ The primary endpoint of the Molaee et al study was to quantitate the concentration of cell-secreted tumor necrosis factor alpha (TNFa) into culture medium. TNFa is a pro-inflammatory cytokine secreted by activated macrophages and monocytes that exhibits pleiotropic activity in a number of physiological and pathophysiological responses and may be either inflammatory or immunological. ${ }^{11} \mathrm{TNF}$ is found as a $26 \mathrm{kDa}$ membrane-associated protein that undergoes subsequent proteolytic cleavage in vivo producing a $17 \mathrm{kDa}$ homotrimeric, biologically active mature TNFa protein complex. ${ }^{12}$ TNF may also be proteolytically cleaved by TNFa converting enzyme (TACE) producing a trimeric soluble $51 \mathrm{kDa}$ TNFa (sTN$\mathrm{Fa}$ ). TNFa is produced in many cells where, at low physiological levels, it regulates macrophage and neutrophil chemotaxis. ${ }^{13}$ However, at high levels associated with disease, TNFa produces marked changes in physiology including hypotension, coagulation in

Copyright (C) 2017 The Author(s); Published by Zabol University of Medical Sciences. This is an open-access article distributed under the terms of the Creative Commons Attribution License (http://creativecommons.org/licenses/by/4.0), which permits unrestricted use, distribution, and reproduction in any medium, provided the original work is properly cited. 
the microvasculature, fever, and direct cytotoxic damage to cells or tissues. Thus, a causative role for TNFa is insinuated in many diseases including Crohn disease, inflammatory bowel disease, obesity, and type 2 diabetes. ${ }^{13-15}$ $\mathrm{TNF} \alpha$ mediates these responses by interaction with at least two distinct receptors ubiquitous to most cells, the high affinity TNF receptor 1 (TNFR1 or CD120a) and the low-affinity TNF receptor 2 (TNFR2 or CD120b). ${ }^{16}$ Because of its role in disease, a multitude of therapeutic monoclonal antibodies to TNFa have been developed including infliximab (Remicade), adalimumab (Humira), golimumab (Simponi), or the circulating receptor fusion protein etanercept (Enbrel). ${ }^{16}$

The mitogens used by the authors include the lectins (or carbohydrate-binding proteins), Concanavalin A (Con A), phytohemagglutinin (PHA), and lipopolysaccharide (LPS). These mitogens stimulate signal transduction pathways that involve mitogen-activated protein kinase (MAPK) and result in mitotic cell division. The primary target of both Con A and PHA is their binding to the carbohydrate moiety of lymphocyte membrane glycoproteins. Con A binds to non-reducing terminal D-manosyl and $N$-acetyl-D-glucosamine groups while PHA binds to complex oligosaccharide containing galactose, $\mathrm{N}$-acetylglucosamine, and mannose.$^{17}$ LPS is a component of the Gram-negative bacterial cell wall which is a potent monocyte stimulant and results in copious production of proinflammatory cytokines, including TNFa. ${ }^{18}$ While these mitogens were used in this paper, other reagents that can be used to stimulate cytokine production in diluted whole blood or PBMCs, include pokeweed mitogen (PWM), $\mathrm{PMA} /$ ionomycin, purified protein derivative of tuberculin (PPD), and anti-CD3 as well as anti-CD28 antibodies. In order to fully investigate the optimal stimulation conditions applicable to the MTT assay, all possible mitogens that can be used in such an assay should be tested with the cell type most relevant to the nature of the investigation. However, true optimization requires appropriate experimental design ${ }^{19}$ including appropriate group sizes for statistical evaluation, conduct of a power analysis, replicates, randomization and blinding to both study groups and data analysis. Thus, while the study was conducted using multiple stimulatory concentrations of each mitogen and variable cell incubation times, these other critical aspects of the experimental conditions were not described. Only through rigorous investigation of diverse mitogens using such experimental design and analysis, some convincing data can be derived that would allow the determination of optimized conditions for the use of the MTT assay and cell-mediated TNFa release and quantification. Optimizing all assay components is important since stimulated lymphocytes can produce a myriad of diverse cytokines when activated and the type of cytokine markedly depends on the nature of the stimulating reagent as well as assay study conditions. ${ }^{20}$

The authors evaluated a combination of four different mitogens, alone and in combination, over a range of concentrations with four incubation periods $(24,48,72,96$ hours) in cultured PBMCs. Upon completion of the studies and quantifying the cell stimulation index and levels of TNFa, it was concluded that the optimal conditions for induced cell proliferation were a medium supplemented with a mixture of PHA:Con A (at a concentration of $5 \mu \mathrm{g}$ / $\mathrm{mL}$ each) for an incubation period of 72 hours. It is interesting to note that the authors do not describe why they cultured PBMCs at a concentration of $1 \times 10^{5}$ cells/well. Should it be presumed that this is the optimal cell concentration used in such an assay? Similarly, while a range of mitogen concentrations were used, it does not appear, upon visual inspection of the data presented, that the stimulation index of PHA is truly distinct from PHA:Con A. Although there is a statistical significance assigned to the $5 \mu \mathrm{g} / \mathrm{mL}$ mitogen concentration, there are concerns about the nature of the statistics used. Usually non-clinical studies of the nature conducted by Molaee et al are prospective (or planned) hypothesis-driven studies. When studies are complete, the stochastic (randomly determined) data variables are presumed to have a Gaussian distribution and are usually subjected to analysis of variance (ANOVA) or analysis of covariance (ANCOVA) statistical analysis methods. ${ }^{19}$ Such tests determine if the group means are similar or not by comparing all means simultaneously. If they are not similar (i.e., the $F$ value is statistically significant), then a post hoc test should be undertaken. The $P$ value from either an ANOVA or ANCOVA test is a probability estimate of whether the groups are from a similar or different populations. However, should there be only two study groups, the ANOVA is actually a $t$ test and provides a direct comparison between each of the two groups. ${ }^{19}$ Thus, the nature of the study advises that the $t$ test (and by implication, multiple $t$ tests) should not have been used to render a decision on significance. This is not sufficient because beyond 2 groups it has to be repeated which increases the likelihood of 'significance' by incorrectly rejecting the null hypothesis (a type I error). The use of ANOVA maintains the type I error probability at the designated level.

In the paper of Molaee et al, the authors mention that the TNFa cytokine assay was used to quantify the levels of the cytokine from the supernatant of cultured splenocytes. Splenocytes can be a composite of a number of highly different white blood cell types and can be called such, as long as these cells are either derived from the spleen or isolated and purified from splenic tissue. ${ }^{21}$ However, the authors did not discuss the nature of the 'splenocytes' used in the validation of the cytokine assay. Perhaps is not this an incorrect terminology describing the PBMC culture supernatant described in the paper? This confusion is unfortunate as it does not provide the reader with important study details for implementation and use.

After isolation of human PBMCs, the authors determined the optimal stimulation conditions for activation of the PBMCs by the various mitogens and then measured the TNFa secreted in the supernatant using a commercial ELISA (enzyme linked immunosorbent assay) kit. The ELISA commercial kit used by the authors permits the 
measurement of human TNFa protein levels from samples including serum, plasma, and supernatant from cell cultures. This assay uses a monoclonal antibody (mAb) for human TNFa, immobilized on a microtiter plate, that binds with the secreted human TNFa in the study samples (and the assay standards). During the first incubation phase, cell culture medium samples and assay standards along with a biotinylated $\mathrm{mAb}$ specific for TNFa are incubated simultaneously. After washing the unbound substances away, a streptavidin enzyme (conjugated to horseradish peroxidase) is added. Streptavidin is incubated with the biotinylated human TNFa antibody and washed. Furthermore, a substrate solution is added and incubated for a brief period and then followed by the addition of a stop solution. The reaction produces a color change and absorbance of the color generated is read on a plate reader at a wavelength of $450 \mathrm{~nm}$. The absorbance of the colored product is directly proportional to the concentration of TNF $\alpha$ present in the samples.

Recently there has been developed novel, non-radioisotope, high throughput (HT) screening assays for measurement of secreted human TNFa from THP-1 (human leukemia monocytic cell line) cell culture media. ${ }^{14}$ The HTRF (Homogenous Time-Resolved Fluorescence) assay combines measurement of standard FRET (fluorescence resonance energy transfer) technology with time-resolved fluorescence which can be added and incubated for a brief period and this is followed by the addition of a stop solution. The reaction produces a color change and absorbance of the color generated is read on a plate reader at a wavelength of $450 \mathrm{~nm} \cdot{ }^{14,15}$ The absorbance of the colored product is directly proportional to the concentration of TNFa present in the samples.

Another assay, although less convenient method to quantitate $\mathrm{TNF} \alpha$, is the radioisotope labeled immune assay. ${ }^{14}$ This assay is as cumbersome as the ELISA method, because it involves numerous protracted incubation periods and requires wash steps and generates vast quantities of radioactive waste. As a result, there is less usage as an HT method in drug screening programs eliminating shortlived background fluorescence. In this assay, two TNFa mAb's are labeled with Europium(III) trisbipyridine cryptate (the donor fluorophore) and the phycobiliprotein allophycocyanin (APC or XL655, the acceptor fluorophore), respectively. In the absence of TNFa, there is no FRET between these two labeled mAb's, which can produce a fluorescent signal at $615 \mathrm{~nm} \cdot{ }^{22}$ However, in the presence of TNFa, the two labeled antibodies are moved into close proximity and this allows for a FRET transfer to occur between the donor and acceptor fluorophores. ${ }^{14}$ This reaction produces a florescence signal at $665 \mathrm{~nm}$. The increase of FRET levels is proportional to the concentration of TNFa. Unlike previous assays, HTRF maximizes the signal-to-noise ratio of the findings.

The AlphaLISA ${ }^{\circledR}$ (Amplified Luminiscent Proximity Homogenous) immunoassay (PerkinElmer, Waltham, MA) is a bead-based assay that was developed from a diagnostic assay technology known as LOCI (Luminescent
Oxygen Channeling Assay). ${ }^{23,24}$ In this chemiluminescent assay, singlet oxygen molecules generated by high energy laser irradiation (at $680 \mathrm{~nm}$ ) of donor beads excite acceptor beads. This results in a chemical cascade that yields an emission signal at $615 \mathrm{~nm}^{25}$ AlphaLISA ${ }^{\star}$ assays use streptavidin-coated donor beads that capture the biotinylated anti-TNFa antibody and acceptor beads conjugated with a TNFa specific antibody. ${ }^{24}$ All are coated in a layer of hydrogel that provides the necessary functional groups for bio-conjugation if the beads are within $200 \mathrm{~nm}$ from one another due to the capture of the analyte by the mAb's. ${ }^{24}$ The change in light emission is proportional to the concentration of TNFa present.

Thus, the use of HTRF and AlphaLISA ${ }^{\circledR}$ assays regarding the mitogen stimulation of PBMCs may provide greater resolution of stimulation indices when used in conjunction with the MTT assay for cellular quantitation of cytokines such as TNFa. Only through integration of rigorous study design and data analysis, elimination of untoward sources of variance and complete examination, and optimization of each aspect of the experimental study conditions can the MTT assay be truly optimized for use in research and discovery as well as drug safety.

\section{Ethical Approval}

Not applicable.

\section{Competing Interests}

None.

\section{References}

1. Molaee N, Mosayebi G, Pishdadian A, Ejtehadifar M, Ganji A. Evaluating the proliferation of human peripheral blood mononuclear cells using MTT assay. Int J Basic Sci Med. 2017;2(1):25-28. doi:10.15171/ijbsm.2017.06.

2. Mosmann T. Rapid colorimetric assay for cellular growth and survival: Application to proliferation and cytotoxicity assays. J Immunol Methods. 1983;65:55-63. doi:10.1016/0022-1759(83)90303-4.

3. Vega-Avila E, Pugsley MK. An overview of colorimetric assay methods used to survival or proliferation of mammalian cells. Proc West Pharmacol Soc. 2011;54:1014.

4. Hansen BM, Nielsen ES, Berg K. Re-examination and further development of a precise and rapid dye method for measuring cell growth/cell kill. J Immunol Methods 1989;119:203-210. doi:10.1016/0022-1759(89)90397-9.

5. Niks M, Otto, MJ. Towards and optimized MTT assay. J Immunol Methods. 1990;130:149-151.

6. Gerlier D, Thomasset N. Use of MTT colorimetric assay to measure cell activation. J Immunol Methods. 1986;94 (12):57-63. doi:10.1016/0022-1759(86)90215-2.

7. Reyes-Chilpa R, Estrada-Muñiz E, Vega-Avila E, Abe F, Kinjo J, Hernández-Ortega S. Trypanocidal constituents in plants. 7. Mammea-type coumarins. Mem Inst Oswaldo Cruz. 2008;103(5):431-436.

8. Fotakis G, Timbrell JA. In vitro cytotoxicity assays: comparison of LDH, neutral red, MTT and protein assay in hepatoma cells lines following exposure to cadmium chloride. Toxicol Lett. 2006;160:171-177.

9. Böyum A. Isolation of mononuclear cells and granulocyte 
from human blood. Scan J Clin Lab Invest 1968;21 (Suppl 97):77-89.

10. Fuss IJ, Kanof ME, Smith PD, Zola H. Isolation of whole mononuclear cells from peripheral blood and cord blood. Curr Protoc Immunol. 2009;Chapter 7:Unit7.1. doi:10.100 2/0471142735.1m0701s85.

11. Bielecki M, Slawinska E, Lapinska A, Chyczewski L, Kowal-Bielecja O, Kowal K. Effects of tumor necrosis alpha (TNF-alpha) on production or proliferation-inducing ligand (APRIL) by peripheral blood mononuclear cells of systemic sclerosis patients. Int Rev Allergol Clin Immunol. 2010;16(3-4):71-74.

12. Pugsley MK. Etanercept immunex. Curr Opin Investig Drugs. 2001;2(12):1725-1731.

13. Kalliolias GD, Ivashkiv LB. TNF biology, pathogenic mechanisms and emerging therapeutic strategies. Nature Reviews Rheumatology. 2016;12:49-62. doi:10.1038/ nrrheum.2015.169.

14. Leister KP, Huang R, Goodwin BI, Chen A, Austin CP, Xia $M$. Two high throughput screen assays for measurement of TNF- $\alpha$ in THP-1 cells. Curr Chem Genomics. 2011;5:2129. doi:10.2174/1875397301105010021.

15. Gambino R, Bo S, Signorile A, Menato G, Pagano G, Cassader M. Comparison of two enzyme immunometric assays to measure tumor necrosis factor-alpha in human serum. Clinica Chimica Acta 2006;364:349-353. doi:10.1016/j.cca.2005.07.018.

16. Sedger LM, McDermott MF. TNF and TNF-receptors: From mediators of cell death and inflammation to therapeutic giants - past, present and future. Cytokine Growth Factor Rev. 2014;25:453-472. doi:10.1016/j.cytogfr.2014.07.016

17. Norian R, Delirezh N, Azadmehr A. Evaluation of proliferation and cytokines production by mitogenstimulated bovine peripheral blood mononuclear cells. Vet
Res Forum. 2015; 6(4):265-271.

18. van der Bruggen T, Nijenhuis S, van Raaij E, Verhoef J, van Asbeck BS. Lipopolysaccharide-induced tumor necrosis factor alpha production by human monocytes involves the Raf-1/MEK1-MEK2/ERK1-ERK2 pathway. Infect Immun. 1999;67(8):3824-3829.

19. Curtis MJ, Bond RA, Spina D, et al. Experimental design and analysis and their reporting: new guidance for publication in BJP. Br J Pharmacol. 2015;172(14):34613471. doi:10.1111/bph.12856

20. Ai W, Li H, Song N, Li L, Chen H. Optimal method to stimulate cytokine production and its use in immunotoxicity assessment. Int J Environ Res Public Health. 2013;10:38343842. doi:10.3390/ijerph10093834.

21. Montgomery DW, Zukoski CF, Shad GN, Buckley AR, Tadeus P, Russell DH. Concanavaline A-stimulated murine splenocytes produce a factor with prolactin-like bioactivity and immunoreactivity. Biochem Biophys Res Commun. 1987;145(2):692-698. doi:10.1016/0006-291X(87)91020-5.

22. Harbert C, Marshall J, Soh S, Steger K. Development of a $\mathrm{HTRF}^{\circledR}$ kinase assay for determination of Syk Activity. Curr Chem Genomics, 2008;1:20-26. doi:10.2174/187539 7300801010020 .

23. Ullman EF, Kirakossian H, Switchenko AC, et al. Luminescent oxygen channeling assay (LOCI): sensitive, broadly applicable homogeneous immunoassay method. Clin Chem. 1996;42(9):1518-1526.

24. Beaudet L, Rodriguez-Suarez R, Venne $\mathrm{MH}$, et al. AlphaLISA immunoassays: the no-wash alternative to ELISAs for research and drug discovery. Nat Methods. 2008:5(2). doi:10.1038/nmeth.f.230.

25. Eglen RM, Reisine T, Roby P, et al. The use of AlphaScreen technology in HTS: current status. Curr Chem Genomics. 2008;1:2-10. doi:10.2174/1875397300801010002. 